becoming undone 


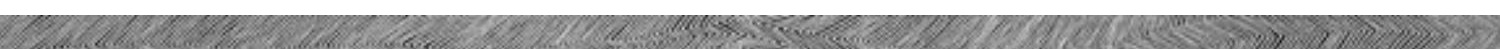

W. w.

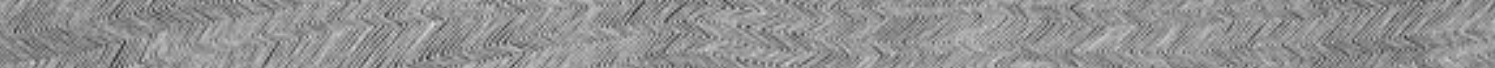

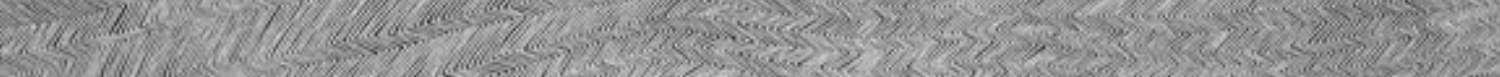

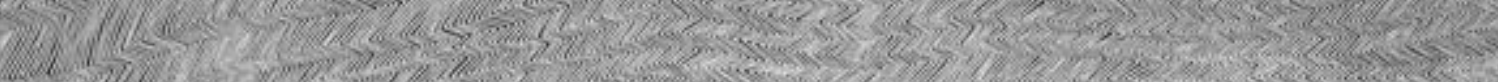

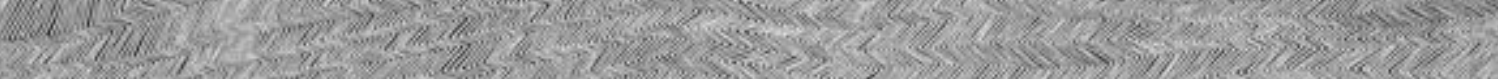

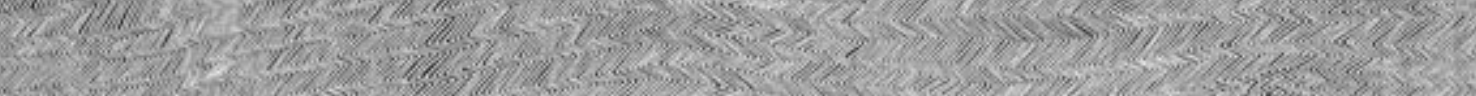

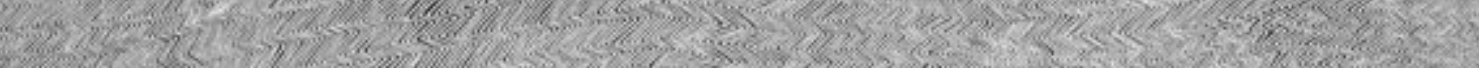

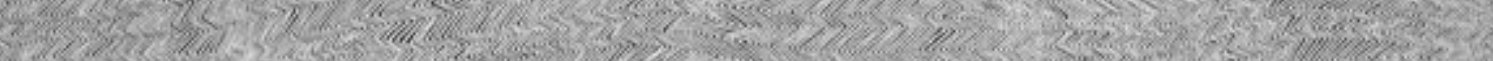

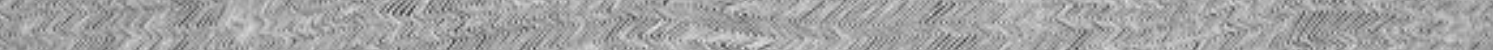
Q

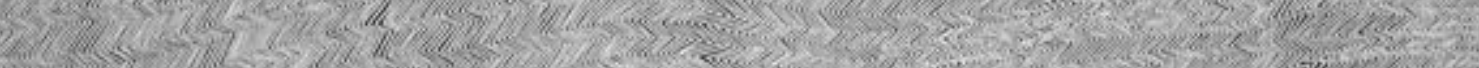

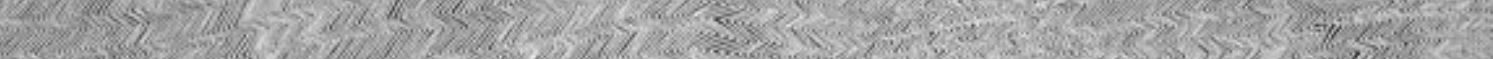

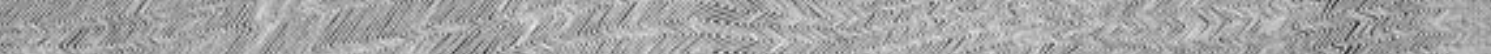

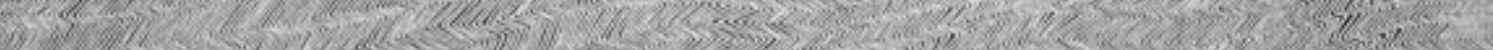

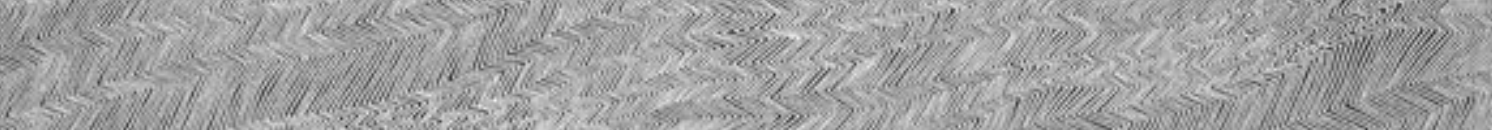
(5)

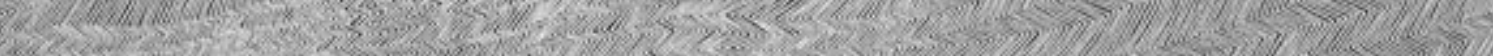

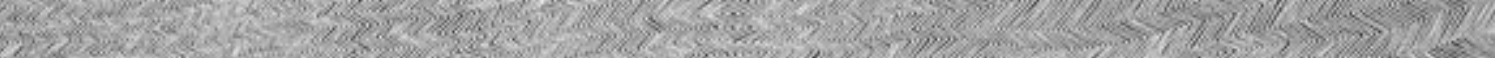

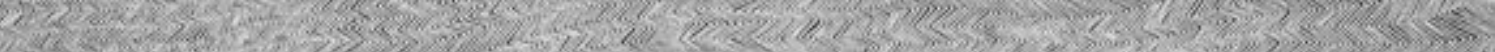

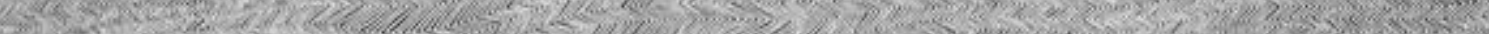

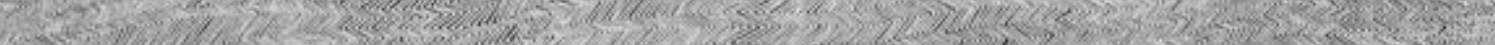

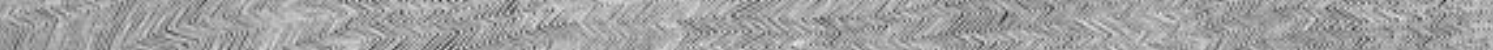

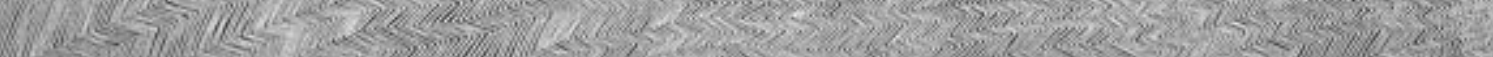

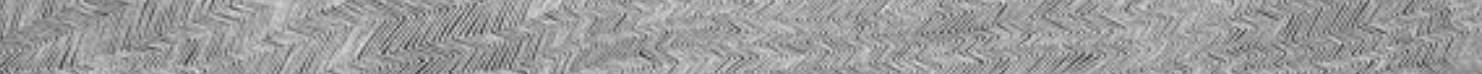

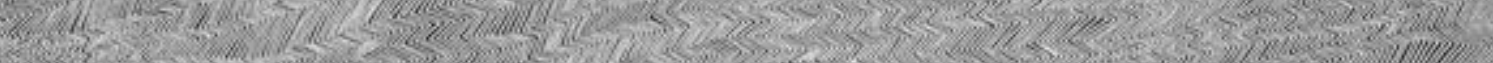
(6.6.

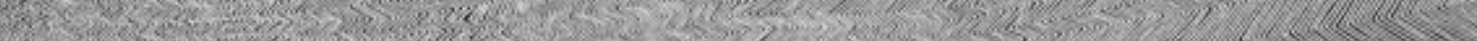

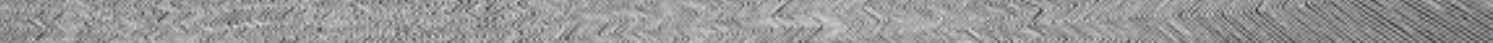
W. 


\section{becoming undone}

DARWINIAN REFLECTIONS ON LIFE, POLITICS, AND ART

ELIZABETH GROSZ

DUKE UNIVERSITY PRESS Durham \& London 20 I I 
(C) 20 I I Duke University Press

All rights reserved

Printed in the United States of America on acid-free paper $\infty$ Designed by Amy Ruth Buchanan

Typeset in Carter + Cone Galliard by Keystone Typesetting, Inc. Library of Congress Cataloging-in-Publication Data appear on the last printed page of this book.

Frontispiece: Untitled, Doreen Reid Nakamarru. Copyright estate of the artist, 20Io, licensed by Aboriginal Artists Agency. 